\title{
Investigation of the relationship between placenta trace element levels and methylated arginines
}

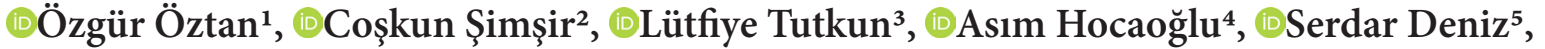 \\ ๑DVugar Ali Türksoy ${ }^{6}, \oplus$ Mehmet Erdem Alagüney $^{7}$ \\ ${ }^{1}$ HLC Medical Center, Department of Medical Management, Ankara, Turkey \\ ${ }^{2}$ Yüksek İhtisas University, Faculty of Medicine, Department of Obstetrics and Gynecologia, Ankara, Turkey \\ ${ }^{3}$ Gazi University, Health Science Faculty, Department of Nutrition and Dietetics, Ankara, Turkey \\ ${ }^{4}$ Ministry of Health Turkish Medicines and Medical Devices Agency, Ankara, Turkey \\ ${ }^{5}$ Malatya Provincial Health Directorate, Malatya, Turkey \\ ${ }^{6}$ Yozgat Bozok University, Department of Public Health, Yozgat, Turkey \\ ${ }^{7}$ Health Sciences University, Konya Şehir Hospital, Occupational Medicine Department, Konya, Turkey
}

Cite this article as: Öztan Ö, Şimşir C, Tutkun L, et al. Investigation of the relationship between placenta trace element levels and methylated arginines. J Health Sci Med 2021; 4(5): 746-751.

\begin{abstract}
Aim: Environmental exposure and maternal nutrition are vital for placental and fetal development during pregnancy. Essential elements such as zinc, copper and selenium are important elements that are needed for human growth and development. Research indicates that methylated arginines play a key role in pregnancy and offspring outcomes. The aim of the study was to compare the placental tissue levels of trace elements and methylated arginines. In addition, we aimed to evaluate this placental trace elements and methylated arginine levels in terms of placental and birth weight.

Material and Method: This is a case-control study with 133 pregnant women. Two groups were formed: women with higher risk of exposure to chemicals (working in chemistry, metal and other industrial sectors) and those with no risk of exposure to hazardous chemicals (house wives and working in other non-hazardous workplaces). Placenta zinc, copper and selenium and asymmetric dimethylarginine, symmetric dimethylarginine, arginine, citrulline, homoarginine and L-N-monomethyl arginine levels were investigated.

Results: There was a positive correlation between birth weight with copper, L-N-monomethyl arginine, total methylarginines; there was a negative relationship between birth weight and asymmetric dimethylarginine, symmetric dimethylarginine, arginine, citrulline. However, no statistically significant relationship was found between trace elements such as zinc, copper and selenium with methylated arginines, except for $\mathrm{L}-\mathrm{N}$-monomethyl arginine $(\mathrm{r}=0.178 ; \mathrm{p}<0.05)$.

Conclusion: Zinc, copper and selenium levels are not related to processes that reduce birth weight and vascular factors.
\end{abstract}

Keywords: Essential elements, methylated arginines, placental weight, birth weight, placenta tissue

\section{INTRODUCTION}

Essential elements such as zinc $(\mathrm{Zn})$, copper $(\mathrm{Cu})$ and selenium (Se) are important elements for human growth and development $(1,2) . \mathrm{Zn}$ is involved in metabolic and physiological processes that control cell growth, while $\mathrm{Cu}$ plays an important role in the absorption and metabolism of Fe. On the other hand, Se is the most well-known trace element necessary for metabolism of organism $(2,3)$. Low levels of $\mathrm{Zn}$ and $\mathrm{Cu}$ are independently associated with a risk of low birth weight $(4,5)$.

Environmental exposures and maternal nutrition are vital for placental and fetal development during pregnancy (4,6-8). Arginine, a semi-essential amino acid, is a precursor in the synthesis of many molecules including nitric oxide and polyamines $(8,9)$. Arginine plays a decisive role in nutrition and metabolism, acting as a precursor for the synthesis of biologically important substances $(6,7)$. Nitric oxide (NO) and polyamines play a decisive role during pregnancy and fetal development (8). Furthermore, these molecules are key regulators of angiogenesis (10). Several studies have demonstrated that polyamines and $\mathrm{NO}$ are essential for placental growth and angiogenesis, therefore increasing uterine and placental-fetal blood flow (11). 
Asymmetric dimethyl arginine (ADMA) is a competitive endogenous inhibitor of nitric oxide (NO) synthase which plays a role in the regulation of NO synthesis (12). Maternal plasma ADMA levels decrease in early stage of gestation but increase as the gestational age increases (13). Asymmetric dimethyl arginine is generated when arginine residues in the nuclear proteins are methylated through the action of the protein arginine methyltransferases $(12,14,15)$. Types of protein arginine methyltransferases were type 1, catalyzing the formation of ADMA, and type 2 , catalyzing the formation of the symmetric dimethyl arginine (SDMA); both generating the NG-monomethylL-arginine (L-NMMA). While asymmetrical methylated species (ADMA and L-NMMA) can inhibit NOS, SDMA cannot $(16,17)$. The vascular endothelium lined with endothelial cells plays a critical role in the mechanics of blood flow, and ADMA antagonizes endotheliumdependent vasodilation. ADMA is accepted to be a strong and independent risk factor of total mortality and inverse vascular outcomes $(12,18,19)$. Citrulline has limited degradation in the placenta, is efficiently transferred from maternal circulation to fetus in favor of fetal development (20). Research indicates that methylated arginines play a key role in pregnancy and offspring outcomes.

The aim of this study is to compare the placental tissue levels of trace elements such as $\mathrm{Zn}, \mathrm{Cu}$, and Se and methylated arginines such as ADMA, SDMA, arginine, citrulline, homoarginine and L-NMMA. In addition, we aimed to evaluate the relationship between levels of placental trace elements and methylated arginine levels and placental weight and birth weight.

\section{MATERIAL AND METHOD}

This study was conducted with the approval of Lokman Hekim University Ethics Committee (Date: 24.12.2020, Decision No:2020/008-008). All procedures were carried out in accordance with the ethical rules and the principles of the Declaration of Helsinki.

\section{Study Area and Design}

This study was conducted at the Department of Obstetrics and Gynecology, Liv Hospital, Ankara, Turkey. In the case of a positive pregnancy test, the women were asked to donate placental tissue sample for future analysis and thereafter were invited to the hospital for further examination. 133 women were enrolled in the study. Oral and written informed consent was granted by all women involved in the study. The placenta tissue samples for all analyses including essential elements and methylated arginines collected and stored $-20^{\circ} \mathrm{C}$ until pre-analyses. These samples are collected for analyses of $\mathrm{Zn}, \mathrm{Cu}$, Se, ADMA, SDMA, arginine, citrulline, homoarginine and L-NMMA levels. We included women with a singleton pregnancy between 34 and 41 weeks of gestation. The control group included gestational age-matched pregnant women who had clinically healthy pregnancies without any complications. We formed two groups in the occupational exposure risk of mother: Group 0 with the low-risk maternal occupation and Group 1with highrisk maternal occupation). Information related to age, body mass index (BMI), socioeconomic status (SES), parity, gestational days, characteristics of the new-born (birth weight, birth length and head circumference) and placental weight were evaluated within the scope of the study. Two groups were formed: women with higher risk of exposure to chemicals (working in chemistry, metal and other industrial sectors) and those with no risk of exposure to hazardous chemicals (house wives and working in other non-hazardous workplaces).

\section{Laboratory Analysis of $\mathrm{Zn}, \mathrm{Cu}$, Se and Methylated Arginine Derivatives}

Placenta tissues were stored frozen, after thawing at room temperature; the wet tissues were weighed on a precision scale, and then transferred onto a glass table. The surfaces of the glass tray and table were pre-dried at $75^{\circ} \mathrm{C}$ for 24 $\mathrm{h}$ in an incubator. Tissue samples collected from the incubator (approximately 0.2 gr per sample) were weighed to determine dry matter using a precision scale and transferred to high temperature resistant microwave Teflon tubes. Dry tissue weights were used in all calculations related to placenta. All tissue samples were digested by Microwave Digestion System (Start D, Milestone, USA). Briefly, $10 \mathrm{ml}$ of nitric acid (Suprapur, $65 \% \mathrm{HNO}_{3}$ ) was added to the tissues, acid etching was performed in the microwave and the tissue specimens were transferred to 15 $\mathrm{ml}$ polypropylene tubes (Isolab) with a rotary cap. The total volume was adjusted to $10 \mathrm{ml}$ with ultrapure water (4). The placenta samples $\mathrm{Zn}, \mathrm{Cu}$ and Se levels were determined using inductively coupled plasma mass spectrometry (ICPMS, Thermo Scientific ICAPQc, USA). The operating parameters were set as follows: radiofrequency power $1550 \mathrm{~W}$, nebulizer gas $0.97 \mathrm{~L} / \mathrm{min}$, plasma gas $0.9 \mathrm{~L} / \mathrm{min}$, nebulizer pressure $3.00 \mathrm{bar}$, dwell time 0.01 milliseconds, and spray chamber temperature $3.6^{\circ} \mathrm{C}$. The sampler probe was washed between injections by rinsing with ultrapure water for $30 \mathrm{~s}$, followed by washing with $2 \% \mathrm{HNO}_{3}$ for $45 \mathrm{~s}$, and finally rinsing with ultrapure water for $45 \mathrm{~s}$. After the washing steps, the instrument automatically ran the next sample. A 9-point (0.5-250 ppb) calibration curves were formed for $\mathrm{Zn}, \mathrm{Cu}$ and $\mathrm{Se}$. A minimum $\mathrm{R}$ value of 0.9985 was calculated for all calibrations. The limit of detection (LOD) of $\mathrm{Zn}, \mathrm{Cu}$ and Se were determined based on the standard deviation of the response and the slope of the calibration curves (3). Method validations were performed with the certified material (Whole Blood L-2, Sero AS, Norway). 
The placenta tissue ADMA, SDMA, arginine, citrulline, homoarginine and L-NMMA levels were determined using a commercially available enzyme-linked immunosorbent assay (ELISA) kit, according to the manufacturer's instructions. The reading of the samples placed on the microplates was done with an ELISA device (BMG LABTECH, UK) with a wavelength of 450 $\mathrm{nm}$. Samples were thawed and each sample was placed on 96-well flat microplates supplemented with $50 \mu \mathrm{L}$ incubation buffers. The microplate was then incubated for $45 \mathrm{~min}$ at $37^{\circ} \mathrm{C}$. After washing and aspiration of microplates (3 times each), $100 \mu \mathrm{L}$ of conjugate was added to the microplates, followed incubate for $30 \mathrm{~min}$ at $37^{\circ} \mathrm{C} .90 \mu \mathrm{L}$ of Reagent was added after second aspiration and washing ( 5 times each). This was followed for $15 \mathrm{~min}$ at $37^{\circ} \mathrm{C}$. Subsequently, stop solutions on microplates were added. Control materials used for optimization and for validity of the ELISA methods. Control samples will be used for verification. The analysis was done in 5 points according to the calibration curves created against the standard measurements in the ELISA device. Each kit was read at least 10 times and regression analysis was performed by taking the averages.

\section{Statistical Analysis}

The SPSS 20.0 software was used in statistical analysis. The suitability of the parameters to the normal distribution was evaluated with the Kolmogorov Smirnov test. It was observed that the data were normally distributed and parametric tests were applied. Continuous variables were presented with their mean and standard deviations. The difference between the two means was evaluated with the t-test, and the relations of the variables with each other were evaluated with Pearson Correlation analysis. $\mathrm{p}<0.05$ and $\mathrm{p}<0.01$ values were considered significant.

\section{RESULTS}

According to Pearson correlation coefficients; there was a positive correlation between birth weight with $\mathrm{Cu}$ $(\mathrm{r}=0.237 ; \mathrm{p}<0.01)$, L-NMMA $(\mathrm{r}=0.202 ; \mathrm{p}<0.05)$, total methylarginines $(r=0.177 ; p<0.05)$; there was a negative relationship between birth weight and ADMA $(r=-0.413$; $\mathrm{p}<0.01)$, SDMA $(\mathrm{r}=-0.273 ; \mathrm{p}<0.01)$, arginine $(\mathrm{r}=-0.192$; $\mathrm{p}<0.05)$, citrulline $(\mathrm{r}=-0.220 ; \mathrm{p}<0.05)$. However, no statistically significant relationship was found between trace elements such as $\mathrm{Zn}, \mathrm{Cu}$ and Se with methylated arginines ( $p>0.05)$, except for L-NMMA $(r=0.178$; $\mathrm{p}<0.05)$. The correlation between clinical parameters is presented in Table 1.

Maternal age, gestational days, birth length, hematocrit (HCT), Zn, $\mathrm{Cu}, \mathrm{Se}$, ADMA, SDMA, arginine, citrulline, homoarginine, L-NMMA, arginine / ADMA ratio, SDMA / ADMA and total methylarginine values were not statistically different between groups ( $p>0.05$ ).

\section{Table 1. The correlation between clinical parameters}

总

\begin{tabular}{|c|c|c|c|c|c|c|c|c|c|c|c|c|c|c|c|c|}
\hline Age & -0.15 & 1 & & & & & & & & & & & & & & \\
\hline $\begin{array}{l}\text { Gestational } \\
\text { days }\end{array}$ & 0.083 & $.203^{*}$ & 1 & & & & & & & & & & & & & \\
\hline HGB & 0.117 & -0.05 & -0.02 & 1 & & & & & & & & & & & & \\
\hline HCT & 0.094 & $-.191^{*}$ & -0.1 & $.442^{* *}$ & 1 & & & & & & & & & & & \\
\hline $\mathrm{Cu}$ & $.237^{* *}$ & -0.15 & -0.15 & 0.04 & $.186^{*}$ & 1 & & & & & & & & & & \\
\hline $\mathrm{Zn}$ & -0.09 & -0.12 & -0.17 & 0.13 & 0.01 & 0.15 & 1 & & & & & & & & & \\
\hline $\mathrm{Se}$ & -0.08 & -0.09 & $-.183^{*}$ & 0.089 & 0.024 & 0.106 & $.877^{* *}$ & 1 & & & & & & & & \\
\hline ADMA & $-.413^{* *}$ & 0.159 & -0.13 & $-.254^{* *}$ & -0.08 & -0.15 & 0.028 & 0.12 & 1 & & & & & & & \\
\hline SDMA & $-.273^{* *}$ & 0.118 & -0.06 & -0.15 & 0.011 & 0.009 & 0.017 & 0.096 & $.572^{* *}$ & 1 & & & & & & \\
\hline Arginine & $-.192^{*}$ & 0.131 & -0.03 & $-.193^{*}$ & -0.05 & -0.11 & -0.07 & 0.002 & $.257^{* *}$ & $.176^{*}$ & 1 & & & & & \\
\hline Citrulline & $-.220^{*}$ & 0.106 & -0.1 & -0.07 & -0.05 & -0.01 & -0.02 & -0.01 & $.205^{*}$ & 0.154 & $.405^{* *}$ & 1 & & & & \\
\hline Homoarginine & 0.004 & 0.043 & -0.17 & -0.02 & -0.07 & 0.106 & -0.11 & -0.14 & $.216^{*}$ & $.186^{*}$ & 0.15 & 0.105 & 1 & & & \\
\hline L-NMMA & $.202^{*}$ & -0.04 & -0.02 & -0.02 & -0.01 & 0.014 & $.178^{*}$ & 0.125 & $-.174^{\star}$ & -0.1 & $-.239^{* *}$ & -0.13 & $-.200^{*}$ & 1 & & \\
\hline $\begin{array}{l}\text { Arginine/ } \\
\text { ADMA ratio }\end{array}$ & 0.013 & 0.064 & 0.029 & -0.07 & -0.02 & -0.05 & -0.09 & -0.05 & $-.194^{*}$ & -0.07 & $.878^{* *}$ & $.291^{* *}$ & 0.074 & -0.16 & 1 & \\
\hline $\begin{array}{l}\text { SDMA/ADMA } \\
\text { ratio }\end{array}$ & 0.115 & -0.08 & 0.075 & 0.103 & 0.097 & 0.152 & 0.024 & 0.008 & $-.395^{* *}$ & $.502^{\star *}$ & -0.05 & -0.05 & -0.01 & 0.062 & 0.152 & 1 \\
\hline $\begin{array}{l}\text { Total } \\
\text { methylarginines }\end{array}$ & $.177^{*}$ & 0.079 & -0.11 & -0.15 & 0.05 & 0.083 & 0.034 & 0.14 & $.649^{* *}$ & $.786^{* *}$ & 0.128 & 0.087 & $.243^{* *}$ & 0.091 & -0.15 & $.188^{*}$ \\
\hline
\end{tabular}


In spite of that, placental weight values for mothers with low-risk occupation group was found statistically significantly higher than mothers with occupations that have higher risk for chemical exposure $(\mathrm{p}<0.05)$. On the contrary, hemoglobin (HGB) levels were found to be statistically significantly lower in mothers with low risk of exposure $(\mathrm{p}<0.05)$. However, the difference was not clinically significant. Therewithal, birth weights were higher for the offspring of mothers with low risk

Table 2. The relationship between clinical parameters according to the occupational exposure risk of mother (0- low-risk maternal occupation group; 1-high-risk maternal occupation group).

\begin{tabular}{|c|c|c|c|c|c|}
\hline & Groups & $\mathbf{n}$ & Mean & $\begin{array}{c}\text { Std. } \\
\text { Deviation }\end{array}$ & $\mathbf{p}$ \\
\hline \multirow{2}{*}{$\begin{array}{l}\text { Maternal Age } \\
\text { (years) }\end{array}$} & 0 & 118 & 27.82 & 5.52 & \multirow{2}{*}{$>0.05$} \\
\hline & 1 & 15 & 28.87 & 5.64 & \\
\hline \multirow{2}{*}{ Gestational Days } & 0 & 118 & 257.58 & 26.75 & \multirow{2}{*}{$>0.05$} \\
\hline & 1 & 15 & 265.07 & 22.89 & \\
\hline \multirow{2}{*}{$\begin{array}{l}\text { Placental Weight } \\
\text { (gr) }\end{array}$} & 0 & 118 & 576.65 & 77.30 & \multirow{2}{*}{$<0.05^{\star}$} \\
\hline & 1 & 15 & 533.00 & 76.90 & \\
\hline \multirow{2}{*}{$\begin{array}{l}\text { Birth Weight } \\
\text { (gr) }\end{array}$} & 0 & 118 & 3181.08 & 417.32 & \multirow{2}{*}{$>0.05$} \\
\hline & 1 & 15 & 3057.33 & 515.08 & \\
\hline \multirow{2}{*}{$\begin{array}{l}\text { Birth Length } \\
(\mathrm{cm})\end{array}$} & 0 & 118 & 49.05 & 3.80 & \multirow{2}{*}{$>0.05$} \\
\hline & 1 & 15 & 50.07 & 3.17 & \\
\hline \multirow{2}{*}{$\begin{array}{l}\text { Head } \\
\text { Circumference }\end{array}$} & 0 & 118 & 33.82 & 1.20 & \multirow{2}{*}{$>0.05$} \\
\hline & 1 & 15 & 34.40 & 1.06 & \\
\hline \multirow{2}{*}{ HGB } & 0 & 118 & 12.05 & 1.50 & \multirow{2}{*}{$<0.05^{\star}$} \\
\hline & 1 & 15 & 13.03 & 1.99 & \\
\hline \multirow{2}{*}{ HCT } & 0 & 118 & 38.13 & 14.20 & \multirow{2}{*}{$>0.05$} \\
\hline & 1 & 15 & 39.39 & 14.13 & \\
\hline \multirow{2}{*}{$\mathrm{Cu}[\mathrm{ug} / \mathrm{g}]$} & 0 & 118 & 27.03 & 18.64 & \multirow{2}{*}{$>0.05$} \\
\hline & 1 & 15 & 25.17 & 21.38 & \\
\hline \multirow{2}{*}{ Zn [ug/g] } & 0 & 118 & 77.77 & 110.21 & \multirow{2}{*}{$>0.05$} \\
\hline & 1 & 15 & 96.82 & 160.62 & \\
\hline \multirow{2}{*}{ Se [ug/g] } & 0 & 118 & 2.92 & 3.09 & \multirow{2}{*}{$>0.05$} \\
\hline & 1 & 15 & 3.25 & 4.20 & \\
\hline \multirow{2}{*}{$\begin{array}{l}\text { ADMA } \\
\text { (umol/L) }\end{array}$} & 0 & 118 & 0.73 & 0.16 & \multirow{2}{*}{$>0.05$} \\
\hline & 1 & 15 & 0.71 & 0.14 & \\
\hline \multirow{2}{*}{ SDMA (umol/L) } & 0 & 118 & 0.91 & 0.22 & \multirow{2}{*}{$>0.05$} \\
\hline & 1 & 15 & 0.90 & 0.12 & \\
\hline Arginine & 0 & 118 & 669.97 & 305.90 & $>0,05$ \\
\hline (umol/L) & 1 & 15 & 663.35 & 288.43 & 3.05 \\
\hline Citrulline & 0 & 118 & 52.27 & 41.39 & $>0.05$ \\
\hline (umol/L) & 1 & 15 & 52.68 & 39.08 & \\
\hline Homoarginine & 0 & 118 & 3.04 & 2.36 & $>0.05$ \\
\hline (umol/L) & 1 & 15 & 2.67 & 2.62 & $>0.05$ \\
\hline L-NMMA & 0 & 118 & 0.07 & 0.06 & $>0.05$ \\
\hline (umol/L) & 1 & 15 & 0.06 & 0.05 & 2.03 \\
\hline Arginine/ & 0 & 118 & 937.90 & 457.63 & $>0.05$ \\
\hline ADMA oranı & 1 & 15 & 927.94 & 350.15 & \\
\hline SDMA/ ADMA & 0 & 118 & 1.26 & 0.25 & $>0.05$ \\
\hline oranı & 1 & 15 & 1.29 & 0.17 & \\
\hline 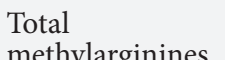 & 0 & 118 & 1.93 & 0.33 & \\
\hline $\begin{array}{l}\text { (umol/L) } \\
\text { (umprargmes }\end{array}$ & 1 & 15 & 1.83 & 0.27 & $>0.05$ \\
\hline
\end{tabular}

of exposure, however the difference was not statistically significant $(\mathrm{p}>0.05)$. Main clinical parameters of variables according to maternal occupation groups presented in Table 2.

While a statistically significant negative correlation was found between birth weight and maternal age mothers with high risk of occupational exposure $(\mathrm{r}=-0.720$; $\mathrm{p}<0.01$ ), this relationship was not significant in the lowrisk group $(r=-0.530 ; p>0.05)$.

Essential element levels and birth weight were compared according to the occupational exposure risk with Pearson correlation coefficients. There was a positive correlation between $\mathrm{Cu}$ and birth weight values in low-risk maternal occupation group $(r=0.340 ; p<0.01)$. On the other hand, there was no significant relationships birth weight with other trace elements. Figure 1 shows relationships between birth weight and analyzed trace elements.

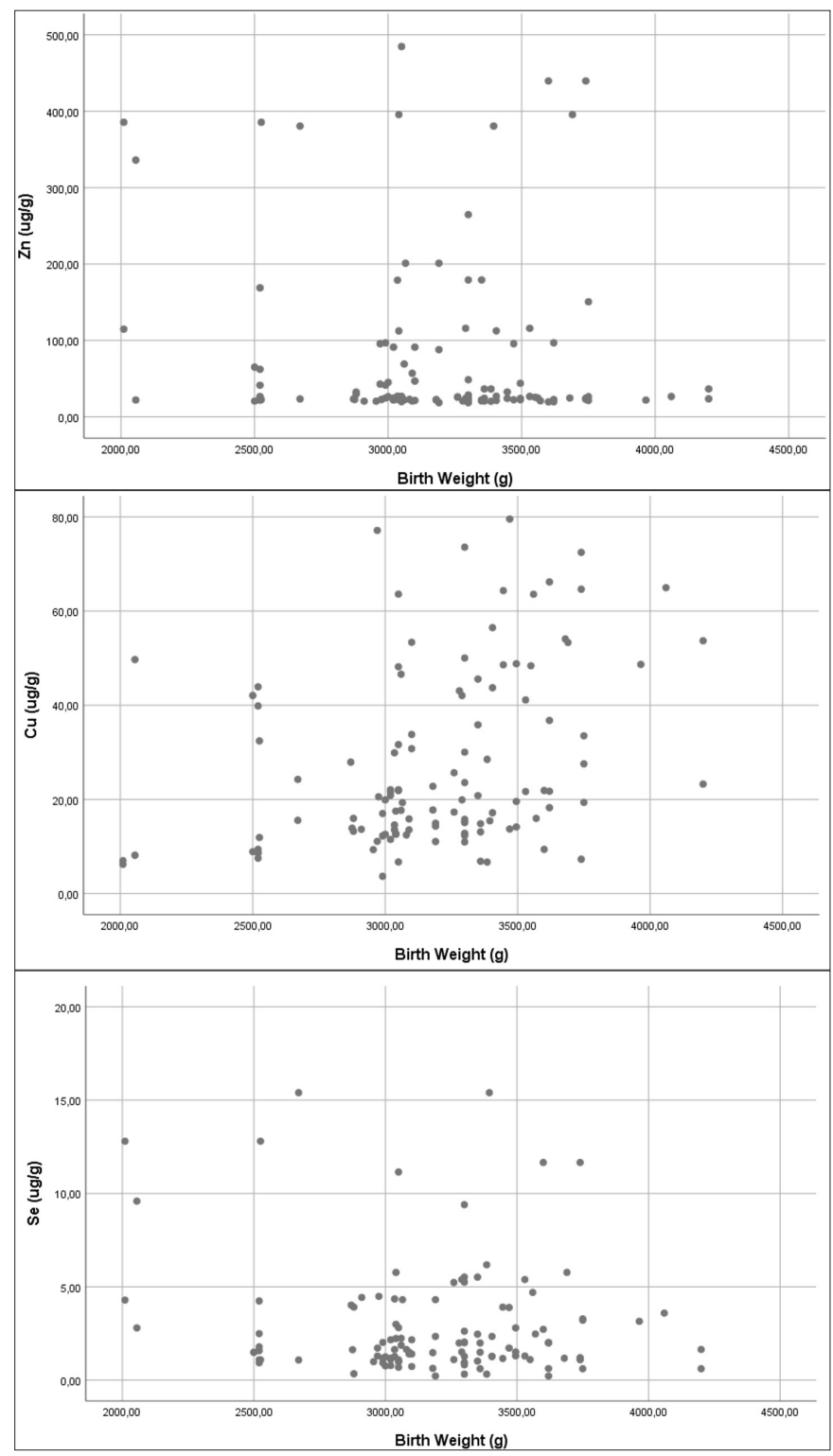

Figure 1. The relationship between birth weight and analyzed trace elements such as $\mathrm{Zn}, \mathrm{Cu}$ and $\mathrm{Se}$. 


\section{DISCUSSION}

The main finding of this study was a negative relationship between birth weight and ADMA, SDMA, arginine and citrulline values. A recent study showed that maternal plasma ADMA concentration may be an indicator of fetal growth restriction (21).

$\mathrm{Cu}$ plays a role in both antioxidant and prooxidant events in human body (3). This element regulates the functions of several cuproenzymes that are essential for life (22). Copper is a trace element which is required for the functioning of variety cellular enzymes $(23,24)$. The data about the relationship between trace elements especially $\mathrm{Cu}$ and methylated arginines is conflicting. Copper amine oxidase, which modulates NO production by regulating arginase activity, affects the bioavailability of arginine (25).

Strong immune response needs adequate level of micronutrients. $\mathrm{Zn}, \mathrm{Cu}$, vitamin $\mathrm{A}$, vitamin $\mathrm{D}$, vitamin $\mathrm{C}$, vitamin $\mathrm{E}$ and other trace elements and vitamins, all of them are described as micronutrient (23). Oral arginine supplementation improved fetoplacental blood flow distribution in pregnant women with threatened preterm labor. These observations suggest that arginine supplementation might have a beneficial effect on preterm birth (8). On the other hand, a positive correlation was found between $\mathrm{Cu}$ levels and birth weight in this study. Özdemir et al. (22) suggested that copper may impair fetal growth with its negative effect on SOD1 enzyme. In the same study, they also stated that $\mathrm{Zn}$ did not have a negative effect on fetal growth. Although, copper was found to have a strong positive correlation with birth weight in the whole group in our study. In this context, while there was a significant relationship in the low-risk maternal occupational exposure group, no relationship was found in highrisk group. This suggests other factors came into play in the low-risk group. On the other hand, there was no significant relationship between birth weight and other trace elements such as $\mathrm{Zn}$ and Se. However, no statistically significant relationship was found between analyzed trace elements with methylated arginines, except for L-NMMA. The reason for the lack of this relationship is that low birth weight in trace element deficiency is not associated with vascular factors. Therefore, it would be appropriate to investigate the relationship of other toxic exposures with this situation in different groups.

\section{CONCLUSIONS}

In conclusion, according to the data we obtained in our study, $\mathrm{Zn}$ and Se trace elements are not related to processes that reduce birth weight and vascular factors.
However, a strong positive correlation was found between $\mathrm{Cu}$ levels and birth weight in this study. This also suggest us to question the necessity of these supplements during pregnancy.

\section{ETHICAL DECLARATIONS}

Ethics Committee Approval: This study was conducted with the approval of Lokman Hekim University Ethics Committee (Date: 24.12.2020, Decision No:2020/008008).

Informed Consent: All patients signed the free and informed consent form.

Referee Evaluation Process: Externally peer-reviewed.

Conflict of Interest Statement: The authors have no conflicts of interest to declare.

Financial Disclosure: The authors declared that this study has received no financial support.

Author Contributions: All of the authors declare that they have all participated in the design, execution, and analysis of the paper, and that they have approved the final version.

\section{REFERENCES}

1. Abass RM, Hamdan HZ, Elhassan EM, Hamdan SZ, Ali NI, Adam I. Zinc and copper levels in low birth weight deliveries in Medani Hospital, Sudan. BMC Res Notes 2014; 7: 386.

2. Kot K, Kosik-Bogacka D, Łanocha-Arendarczyk N, et al. Interactions between 14 Elements in the Human Placenta, Fetal Membrane and Umbilical Cord. Int J Environ Res Public Health 2019; 16: 1615 .

3. Turan E, Turksoy VA. Selenium, Zinc, and Copper Status in Euthyroid Nodular Goiter: A Cross-Sectional Study. Int J Prev Med 2021; $12: 46$

4. Turksoy VA, Yalvac ES, Simsek OT, et al. Impact of zinc on birth and placental weight in cadmium and lead exposure during pregnancy. Indian J Forensic Med Pathol 2019; 12: 246-54.

5. Roels HA, Bowler RM, Kim Y, et al. Manganese exposure and cognitive deficits: a growing concern for manganese neurotoxicity. Neurotoxicology 2012; 33: 872-80.

6. Wu G, Morris SM Jr. Arginine metabolism: nitric oxide and beyond. Biochem J. 1998; 336: 1-17.

7. Wu G, Bazer FW, Satterfield MC, et al. Impacts of arginine nutrition on embryonic and fetal development in mammals. Amino Acids 2013; 45: 241-56.

8. Hsu CN, Tain YL. Impact of arginine nutrition and metabolism during pregnancy on offspring outcomes. Nutrients 2019; 11: 1-15.

9. Wu G, Bazer FW, Davis TA, et al. Arginine metabolism and nutrition in growth, health and disease. Amino Acids 2009; 37: 153-68.

10.Zhao X, Lu X, Feng Q. Deficiency in endothelial nitric oxide synthase impairs myocardial angiogenesis. Am J Physiol Heart Circ Physiol 2002; 283: H2371-H2378.

11. Gao K, Jiang Z, Lin Y, et al. Dietary L-arginine supplementation enhances placental growth and reproductive performance in sows. Amino Acids 2012; 42: 2207-14.

12. Tutkun L, Gunduzoz M, Turksoy VA, et al. Assessment of Endothelial Dysfunction with Methylated Arginines and L-arginine in Cadmium-Exposed People: a Pilot Study. Clin Lab 2019; 65: 10.7754/Clin.Lab.2019.181249. 
13. Fickling SA, Williams D, Vallance P, Nussey SS, Whitley GS. Plasma concentrations of endogenous inhibitor of nitric oxide synthesis in normal pregnancy and pre-eclampsia. Lancet. 1993; 342: 242-3.

14.Emrich IE, Zawada AM, Martens-Lobenhoffer J, et al. Symmetric dimethylarginine (SDMA) outperforms asymmetric dimethylarginine (ADMA) and other methylarginines as predictor of renal and cardiovascular outcome in non-dialysis chronic kidney disease. Clin Res Cardiol 2018; 107: 201-13.

15. Martens-Lobenhoffer J, Bode-Böger SM. Amino acid N-acetylation: metabolic elimination of symmetric dimethylarginine as symmetric $\mathrm{N}(\alpha)$-acetyldimethylarginine, determined in human plasma and urine by LC-MS/MS. J Chromatogr B Analyt Technol Biomed Life Sci 2015; 975: 59-64.

16. Griffioen AW, Molema G. Angiogenesis: potentials for pharmacologic intervention in the treatment of cancer, cardiovascular diseases, and chronic inflammation. Pharmacol Rev 2000; 52: 237-268.

17. Wada $\mathrm{K}$, Inoue $\mathrm{K}$, Hagiwara $\mathrm{M}$. Identification of methylated proteins by protein arginine $\mathrm{N}$-methyltransferase 1, PRMT1, with a new expression cloning strategy. Biochim Biophys Acta 2002; 1591: 1-10.

18.Zoccali C, Bode-Böger S, Mallamaci F, et al. Plasma concentration of asymmetrical dimethylarginine and mortality in patients with end-stage renal disease: a prospective study. Lancet 2001; 358: 2113-7.

19. Shao J, Hou L, Liu J, et al. Indoleamine 2,3-Dioxygenase 1 InhibitorLoaded Nanosheets Enhance CAR-T Cell Function in Esophageal Squamous Cell Carcinoma. Front Immunol 2021; 12: 661357.

20. Lassala A, Bazer FW, Cudd TA, et al. Intravenous administration of L-citrulline to pregnant ewes is more effective than L-arginine for increasing arginine availability in the fetus. J Nutr 2009; 139: 660-5.

21. Tsikas D, Bollenbach A, Savvidou MD. Inverse correlation between maternal plasma asymmetric dimethylarginine (ADMA) and birthweight percentile in women with impaired placental perfusion: circulating ADMA as an NO-independent indicator of fetal growth restriction?. Amino Acids 2018; 50: 341-51.

22. Ozdemir U, Gulturk S, Aker A, Guvenal T, Imir G, Erselcan T. Correlation between birth weight, leptin, zinc and copper levels in maternal and cord blood. J Physiol Biochem 2007; 63: 121-8.

23. The Potential Role of Arginine/Glutamine/Zinc/Copper as Supplemental Immuno-Enhancing Nutrients in Suspected/Infected Sars-Cov-2 Patients. Iar J Med Sci 2020; 1: 20-25.

24. Tapiero H, Townsend DM, Tew KD. Trace elements in human physiology and pathology. Copper. Biomed Pharmacother 2003; 57: 386-98.

25. Groß F, Rudolf EE, Thiele B, Durner J, Astier J. Copper amine oxidase 8 regulates arginine-dependent nitric oxide production in Arabidopsis thaliana. J Exp Bot 2017; 68: 2149-62. 